\title{
Model of Freight Transportation between the Czech Republic and the US
}

\author{
Helena Bínová and Petr Toman \\ Faculty of Transportation Sciences, Czech Technical University, Praha 110 00, Czech Republic
}

\begin{abstract}
Maritime transportation is one of the most important and extensive transportation modes in the world. Maritime transportation is the backbone of contemporary world trade and therefore special attention should be paid to all subjects concerning this mode of transportation. It is also necessary to complement maritime transportation by other modes, such as rail and/or truck (road). This article deals with the problems of maritime transportation and provides the summary of recent developments, trends and statistics mainly on transatlantic maritime routes (Europe to US). Besides maritime transportation, this thesis also reviews the trends and statistics of rail and truck (road) transportation in US and Europe. The authors considers four Czech biggest cities (points of origin), five European ports, eight US ports and 10 biggest cities in US (points of destination). The adapted TCMMSP (transnational collaborative multi-mode shipping problem) is applied to this case study and it seeks to solve the transportation of a set of five shipments with unique O-D (origin-destination) pairs and volume. The end of the thesis summarizes the results and analyses the average costs, optimal set volume, optimal shipment routing and port analysis.
\end{abstract}

Key words: Maritime transport, freight trade, Czech Republic, US.

\section{Introduction}

Maritime transportation is essential for international trade. There is no other mode, perhaps except for air transportation, on how to transport goods between two or more countries which do not have any land connections between.

In US, 1.478 billion tons of freight was transported by sea in the year 2011 [1]. It was almost $75 \%$ of all US international goods trade weight in that year. The gross weight of seaborne goods was handled in European ports in the years 2002-2011. There is an evident increasing trend in years 2002-2007. In the year 2008, the volume of gross weight became stable and, in 2009, it fell sharply. This was caused by the economic recession which hit Europe in 2008 and its consequence can be seen in 2009. From the year 2009, there has been a continuing growth.

One of the most important features of the maritime transportation is its network and its connection with

Corresponding author: Helena Bínová, Ph.D., research fields: intermodal transport and logistics. E-mail: binova@fd.cvut.cz. highway and railway systems. The maritime network has three main routes: transpacific, transatlantic and Europe-Asia.

Section 3 of the article seeks to create a mathematical model of transportation between Europe and US. The line haul is maritime transportation and the complementary modes of transportation from the ports to/from cities (points of destination/origin) are rail and truck (road). The models are formulated for shipping goods from Europe to US. The TCMMSP (transnational collaborative multi-mode shipping problem) had already existed in a different formulations and the author adjusted it to be applicable to the case study.

Section 4 of the article deals with a case study.

\section{World Trade}

\subsection{Merchandise Trade}

World merchandise trade and world seaborne trade have been constantly shaped by the shape of the curve of world GDP (gross domestic product) (Fig. 1). The 


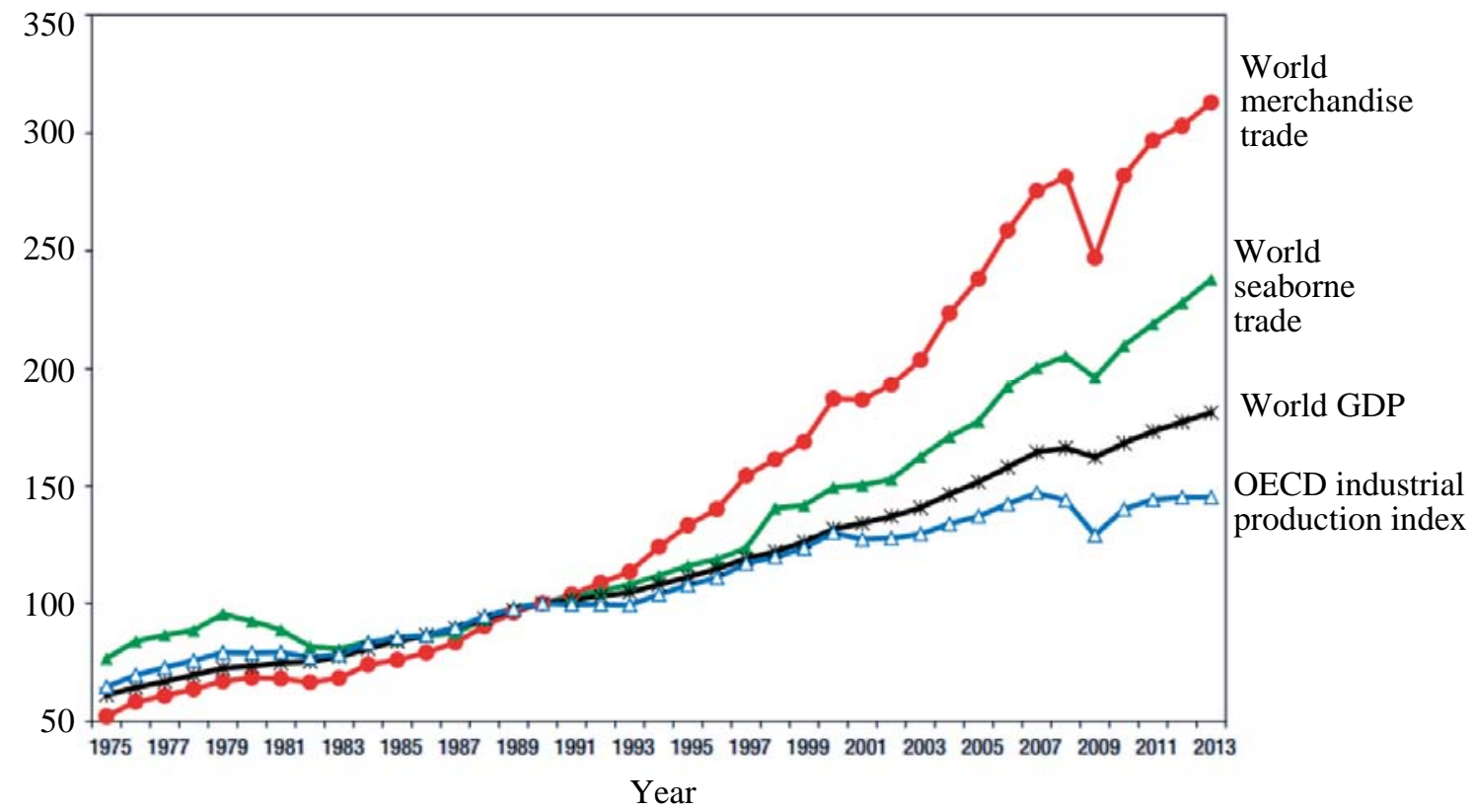

Fig. 1 The OECD (Organization for Economic Co-operation and Development) industrial production index and indices for world GDP, world merchandise trade and world seaborne trade $(1975-2013)(1990=100)$ [2].

development of the maritime transportation and international seaborne trade are highly connected with worldwide macroeconomic conditions.

Global merchandise trade has been growing much faster than GDP [2].

\subsection{World Seaborne Trade}

The amount of world merchandise trade and international seaborne trade has been constantly increasing since the year 1985 [2]. The only exception is in the year 2009, when the international seaborne trade was influenced by the economic recession that hit US and Europe in 2008. During these years, international seaborne trade decreased by 6\% (Fig. 2 ).

\subsection{Transatlantic Route}

This route connects the main ports in the east coast of North America (New York-New Jersey, Savannah, Norfolk, Charleston and Miami) with main ports of western Europe (Rotterdam, Antwerp, Hamburg and Bremerhaven).

The total US investment in the EU (European Union) is three times higher than in all of Asia and
EU investment of US is approximately eight times the amount of EU investment in India and China together. Therefore, these investments are real driver of the transatlantic trade relationship, contributing to growth on both sides of the Atlantic.

Thus, the volume of transported cargo on the transatlantic route could increase [3].

Since EU has proposed to US in March 2013 on a trade and investment agreement called TTIP (Transatlantic Trade and Investment Partnership), the transatlantic route would become increasingly more important for the global trade.

The pendulum route structure also exists in the transatlantic route.

One of them being provided by OOCL (Orient Overseas Container Line) takes in a total of 27 days (including time spent in the ports) and it serves four European ports (Hamburg, Rotterdam, Le Havre and Southampton) and three ports on east coast of the US (New York, Norfolk and Charleston).

\subsection{Container Ships}

Currently, about $90 \%$ of non-bulk cargo in the 


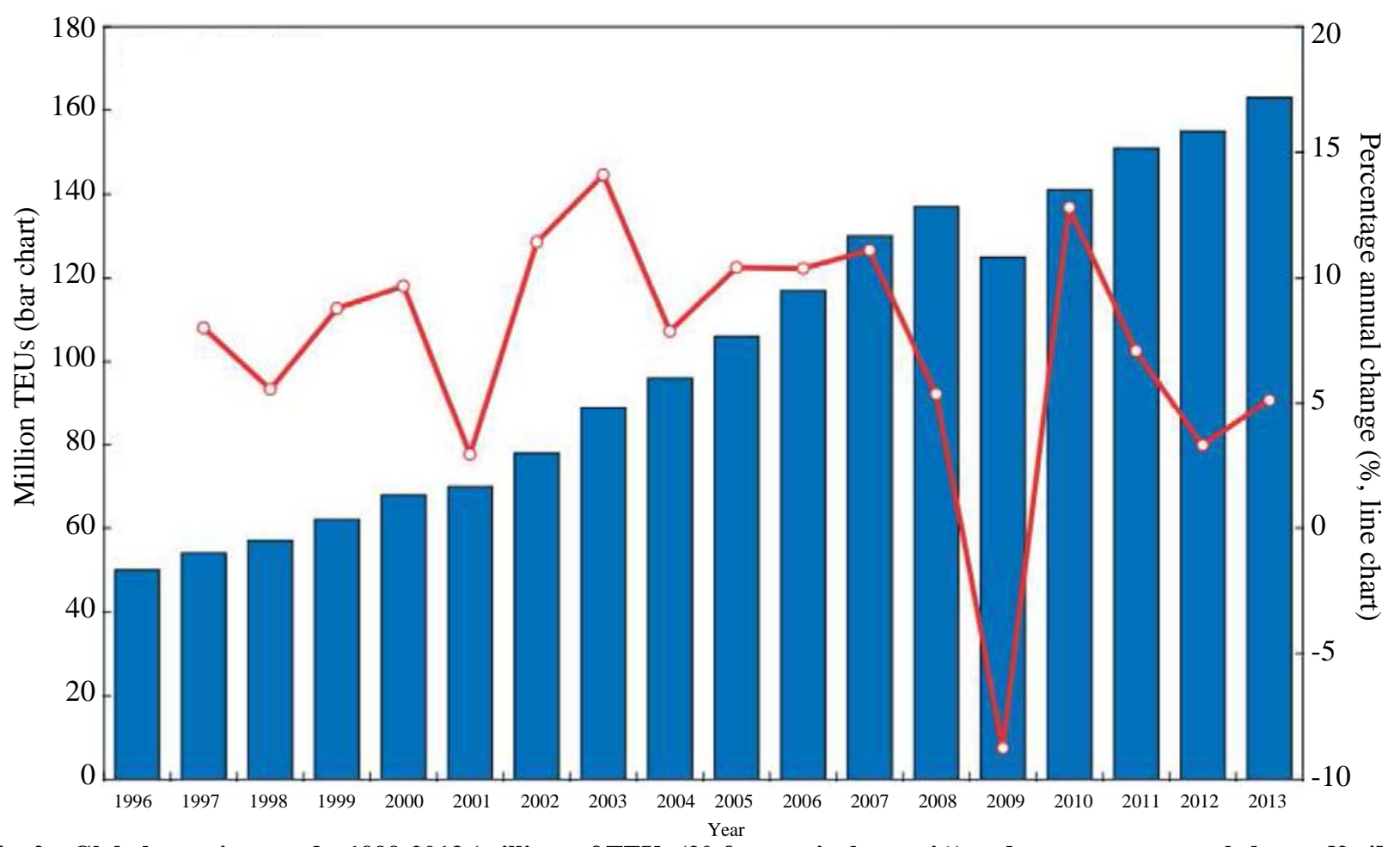

Fig. 2 Global container trade, 1999-2013 (millions of TEUs (20-foot equivalent unit)) and percentage annual change [2, 4].

world is transported in containers and the capacity of vessels capable to carry containers is constantly increasing.

Ships of latest generation Post New Panamax are able to carry up to 15,000 TEUs. Therefore, the capacity of container ships had been constantly increased because the larger the ship is, the lower cost per transported unit is.

The principle of economies of scale is fundamental to the economics of maritime transportation.

\subsection{US Continent}

\subsubsection{Ports}

Maritime ports are very important in logistic chain and they play crucial role in transportation of goods to and from US. $74.96 \%$ of weight of US international merchandise trade in 2011 and $46.90 \%$ of the total value of that international US trade was transported by sea.

In 2004-2009, the number of containership calls at US ports had remained fairly permanent, averaging about 18,000 calls per year. Then, it started to grow by almost 13\% per year and in 2011 the number of calls reached 22,100. Similarly, the volume of containerized freight cargo has been increasing as well [5].

2.5.2 Comparison of Road and Rail Transportation

The fact that the railroads are used mainly for long-distance transportation is caused mainly by the prices of truck and rail intermodal transportation. For distances greater than $500 \mathrm{~km}$, rail transportation of containers costs about $20 \%$ less than road transportation and the cost advantage increases as distance increases [6, 7].

Trucks carry most of the tonnage and value of freight in US, but railroads carry significant volumes over long distances. It is also obvious that higher volume of freight is transported in the east coast than the west coast of US. The average size per call of container vessels that docked at US ports in 2011 was 3,950 TEUs. This is an increase of $22.3 \%$ from about 3,500 TEUs in 2006, as can be seen in Fig. 3. 


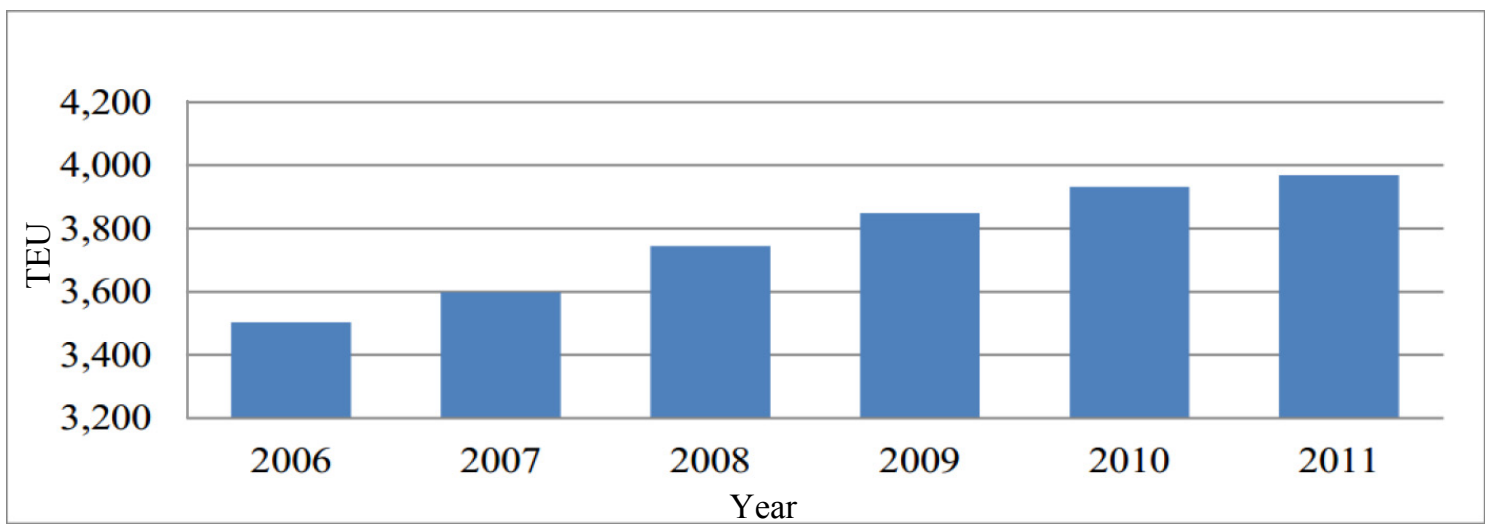

Fig. 3 Average containership size per call at US ports in TEUs (20-foot equivalent unit), 2006-2011 [5, 8].

\section{Export vs. import CR-US (mil. \$)}

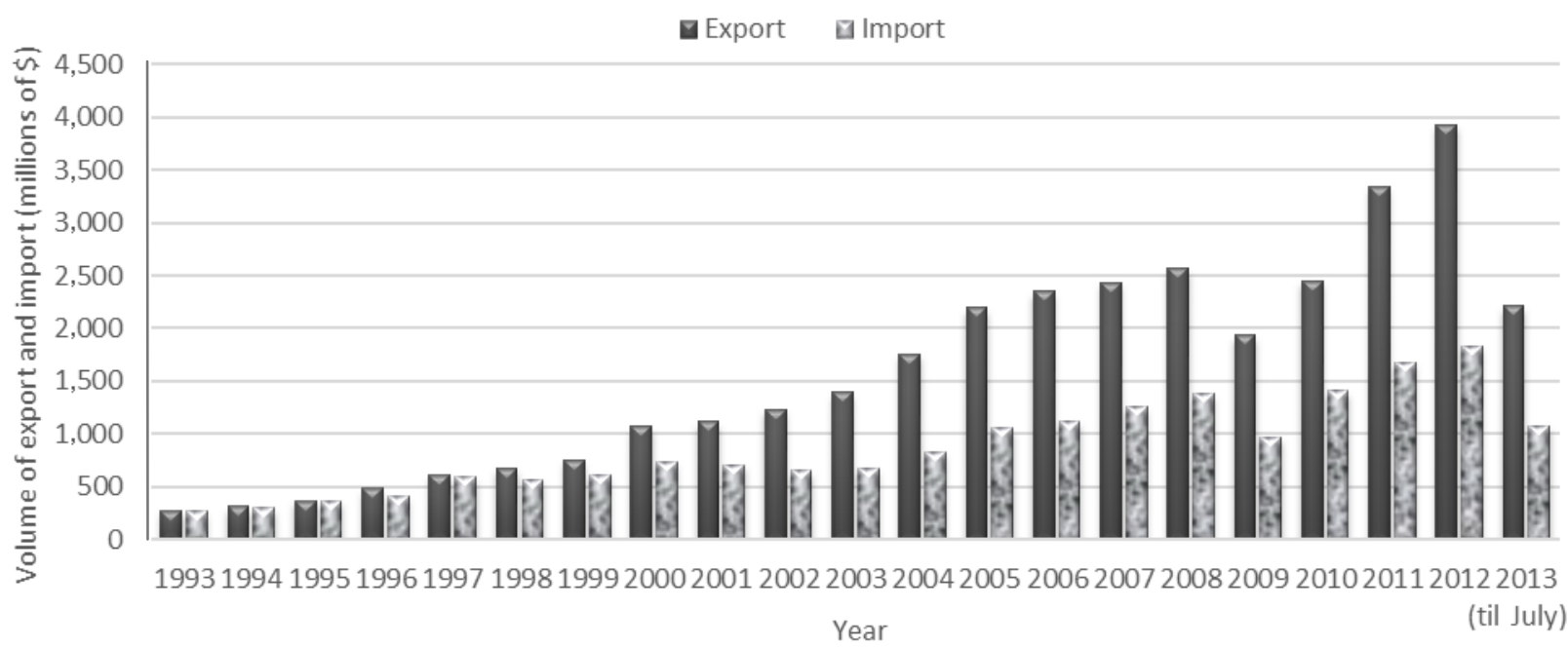

Fig. 4 Volume of export and import CR-US in millions of USD [8, 9].

\subsection{Continent}

Europe is one of the densest port regions in the world. European ports are gateways to the European continent: $74 \%$ of EU goods are shipped through ports and they are definitely crucial for European transportation business and its competitiveness. Over 1,200 commercial seaports operate along some $70,000 \mathrm{~km}$ of EU's coast. In 2011, around 3.7 billion tons of cargo (more than 60,000 port calls of merchant ships) transited through European ports. Bulk traffic represents $70 \%$ of it, container traffic $18 \%$, ro-ro traffic $7 \%$ and the rest was other general cargo [6].

\subsection{Trade between the Czech Republic and the US}

The development of international merchandise trade progressed at an extremely dynamic rate during the postwar period. Between 1950 and 2000, trade volume increased at an average of $6 \%$ annually. Following a drop in merchandise trade in 2001, positive trend has continued in the past few years [10].

The development of the international trade between Czech Republic and US from 1993 to July 2013 is shown in Fig. 4. Data from the charts were obtained on the basis of information on the international trade within the CR (Czech Republic)-US. Foreign trade between the CR and US has had a different 
development trend during the last several years.

The significant drop of international trade between $\mathrm{CR}$ and US recorded is caused by the economic recession in 2008 and its aftermaths can be seen in 2009.

In 2000, basic difference between export and import started. Then import decreased for 2 years (2001 and 2002) and, since those years, export to US has been twice higher than import to CR. Since 2003, the trend has practically been the same for both export and import.

\section{Models of Freight Transportation between Europe and the US}

The following model was originally developed by Hernández and Peeta [11]. The authors used it as a framework and adopted it so the adjusted model is mainly focused on maritime freight transportation across the Atlantic Ocean between Europe and the US. The authors also implemented some modes of inland transportation in the model which complement the maritime transportation. The model consists of network of maritime shipping lines between the ports and then networks of road and railway transportation on both sides of the Atlantic Ocean.

\subsection{Problem Description and Assumptions}

TCMMSP is a problem where logistic companies want to transport shipments to another continent. The formulation includes three modes of transportation, truck, rail and maritime vessel, and is from the perspective of a logistics operator.

The formulation consists of the total costs incurred by different collaborative transportation modes. In addition, the formulation assumes the following: (1) the logistics operator does not prefer any mode of transportation; (2) selected modes meet all the necessary requirements for transporting goods (e.g., refrigeration equipment, the conditions for dangerous goods and etc.); (3) the shipment is not split to multiple vehicles or vessels routes (arcs) of the same mode during a transfer; (4) the total loaded shipment transported by a vessel must not exceed the ship's capacity.

Therefore, the problem is deterministic in the sense that the demand is known. By contrast, a stochastic version would be the unknown and time dependent demand, which would make problem much more complicated. But it is out of the scope of this article.

\subsection{Problem Formulation}

This section describes the mathematical programming formulation. The notation, constraints, and objective function are discussed, followed by the characterization of the formulation properties.

\subsection{Sets}

Let a shipment $q \in Q$ (in TEUs) be served by a set of fixed transshipment facilities $i \in N \quad$ (also labeled facilities or nodes) which are interconnected by links in network $a \in A$ (also labeled arcs). The links in network $a \in A$, those incident from facility $i \in N$, are depicted as $a \in \Gamma(i)$ and those incidents to facility $i \in$ $N$ are $a \in \Gamma^{-1}(i)$.

A shipment $q \in Q$ may be served by a link in the network $a \in A$ only by collaborative modes of transportation $m \in M$ (truck, rail and vessel) operating in this transnational network. Fixed transshipment facilities $i \in N$ and collaborative mode of transportation $m \in M$ form our transportation network. A shipment $q \in Q$ will enter the transportation network through an origin facility $O(q)$ (either US or EU) and exit through a destination node $D(q)$ in a different continent across the Atlantic Ocean. For each shipment $q \in Q$, its origin facility $O(q)$ and its destination node $D(q)$ constitutes its origin-destination pair.

\subsection{Parameters}

Each shipment $q \in Q$ has the demanded volume $w_{q}$. The unit cost incurred by collaborative transportation mode $m \in M$ for transporting a shipment on arc $a \in A$ 
is $\theta_{a m}$ and the fixed cost of transferring for collaborative transportation mode $m \in M$ on arc $a \in A$ is $\varphi_{a m}$.

The available transportation capacity by transportation mode $m \in M$ for link in the network $a$ $\in A$ is $r_{a m}$. If a collaborative transportation mode $m \in$ $M$ does not have sufficient capacity for link in the network $a \in A$, it is assumed without loss of generality that its transportation capacity $r_{a m}$ is 0 .

\subsection{Decision Variables}

If a shipment $q \in Q$ is served through link in the network $a \in A$ by collaborative transportation mode $m$ $\in M$, we define $X_{a m q}$ to take the value of 1 , and 0 otherwise. This variable represents binary variable indicating what kind of transportation is suitable.

If a transfer takes place on link in the network $a \in$ $A$ by collaborative transportation mode $m \in M$, we define $Y_{a m}$ to take the value of 1 , and otherwise. It represents the decision variable for the choose of a transportation mode.

\subsection{Constraints}

In this section, the TCMMSP problem is formulated, which consists of two sets of constraints. The first set of constraints (Eqs. (1)-(3)) models the independent transshipment of shipments through the collaborative transnational multi-mode network. The second set of constraints (Eqs. (4) and (5)) establishes upper bounds on the available collaborative multimode capacity (in terms of volume). The constraints are as follows:

$$
\begin{gathered}
-\sum_{m \in M} \sum_{a \in \Gamma(t)} X_{a m q}=-1 \quad \forall i \in O(q), q \in Q \\
\sum_{m \in M} \sum_{a \in \Gamma^{-1}(i)} X_{a m q}-\sum_{m \in M} \sum_{a \in \Gamma(i)} X_{a m q}=0 \\
\forall i \in N \mid\{O(q), D(q)\}, q \in Q \\
\sum_{m \in M} \sum_{a \in \Gamma^{-1}(i)} X_{a m q}=1 \quad \forall i \in D(q), q \in Q \\
\sum_{a \in \Gamma(t)} Y_{a m} \leq 1 \quad \forall i \in N, m \in M \\
\sum_{q \in Q} w_{q} X_{a m q} \leq r_{a m} Y_{a m} \quad \forall a \in A, q \in Q, m \in M
\end{gathered}
$$

$$
\begin{gathered}
X_{a m q} \in\{0,1\} \quad \forall a \in A, q \in Q, m \in M \\
Y_{a m} \in\{0,1\} \quad \forall a \in A, m \in M
\end{gathered}
$$

Constraint set (Eqs. (1)-(3)) represents the mass balance constraints and ensures the node flow propagation conservation for transportation mode shipment decisions. At most one decision unit of transportation, mode for a shipment is propagated at that facility. It consists of Eqs. (1)-(3), which correspond to the origin, intermediate and destination nodes/facilities in the network, respectively.

Constraint (Eq. (4)) ensures that most one arc/corridor are assigned to a collaborative transportation mode at a facility for a transfer, implying that a shipment is not split to multiple transportation mode routes (arcs) during a transfer.

Constraint (Eq. (5)) represents the collaborative transportation mode capacity constraint; it ensures that the capacity acquired from the collaborative transportation mode (left-hand side of Eq. (5)) is less than its available capacity (right-hand side of Eq. (5)) on that transit corridor. Constraint sets Eq. (6) and Eq. (7) represent the $0-1$ integrality conditions for the decision variables.

\subsection{Objective Function}

The objective function of the TCMMSP problem seeks to minimize the total costs incurred in supply chain during transnational transportation and is represented as follows:

$$
\operatorname{Min} \sum_{a \in A} \sum_{m \in M} \sum_{q \in Q} \theta_{a m} w_{q} X_{a m q}+\sum_{a \in A} \sum_{m \in M} \varphi_{a m} Y_{a m}
$$

It consists of two parts. The first term represents collaborative transportation routing cost of the modes, and the second part denotes the fixed cost of transferring, where transfers occur between modes. The overall collaborative transportation routing cost of modes is obtained as the summation of the product of the collaborative transportation modes total costs incurred for transporting a shipment $\theta_{a m}$, the demand $w_{q}$, and $X_{a m q}$ (the decision on whether a shipment is 
transported on a link in the network). The overall fixed costs of transferring are obtained as the summation of the fixed transfer cost by mode $\varphi_{a m}$ for a link in the network and $Y_{a m}$ (the decision on whether a transfer takes place on that link in network). Eq. (8) subject to constraints Eqs. (1)-(3) through Eq. (7) represents the formulation of the TCMMSP.

The proposed formulation of the TCMMSP belongs to the class of binary (0-1) multi-commodity minimum cost flow problems. It is because the constraints (Eqs. (1)-(3)) are balance node flow constraints on which "flow" propagates.

The classification is further substantiated by the structure of the physical network in which the collaborative transportation modes operate, that is, the static nodes of the collaborative transportation mode network are fixed transshipment facilities (such as ports, depots, warehouses, and/or distribution centers) and the static arcs are links in network corresponding to the collaborative transportation modes. It can be noted that constraints (Eqs. (1)-(3)) can be written independently for each shipment. Constraint set Eq. (4) and Eq. (5) are the transfer arc assignment and the equivalent capacity transportation mode constraints, respectively, which bind the rest of the formulation together [11].

The model provides a tool of network optimization in transportation science. The developed model allows users to determine the optimal collaborative routing in a network system that achieves the minimization of costs for a company that ships a single commodity from multiple origins to multiple destinations. The input parameters are the demand, cost parameters and the network data. The model provides as its output data, the volume carried by each segment and modes and the total costs generated by the whole system.

\section{Application of Model}

This chapter discusses computational experiments performed with TCMMSP model. It evaluates the case study results as well as the implication for practical applications.

\subsection{Case Study}

The case study is about the transportation of several shipments of same kind of product from the Czech Republic to US. Those shipments consist of a single commodity and there are five shipments in total. For the exporting company, the most important factor is the total cost of transportation of all shipments. Therefore, the minimization of cost is crucial and time is not considered. Thus, there is no time-dependency.

For the case study purposes, there are four Czech biggest cities as the points of origin. They are: Prague, Brno, Ostrava and Pilsen. There are five European ports: Rotterdam (Netherlands), Hamburg (Germany), Antwerpen (Belgium), Bremerhaven (Germany) and Le Havre (France).

In US, eight ports are considered. Four ports are on the east coast: Los Angeles (California), Long Beach (California), Oakland (California) and Seattle (Washington), and four on the west coast: New York (New York), Savannah (Georgia), Norfolk (Virginia) and Houston (Texas). The points of destination are the 10 biggest cities in US according to the population in 2012 (City Mayors Statistics 2014). The destinations are: New York (New York), Los Angeles (California), Chicago (Illinois), Houston (Texas), Philadelphia (Pennsylvania), Phoenix (Arizona), San Antonio (Texas), San Diego (California), Dallas (Texas) and San Jose (California).

\subsection{Analysis of Results}

\subsubsection{Average Costs}

Fig. 5 shows cost analysis of 19 sets of shipments. It shows the graph of total costs per TEU, routing costs per TEU, transferring costs per TEU and polynomial regression curve of the third order of total costs per TEU. The first sample Set 1 had infeasible solution due to demand that exceeded capacity.

The minimum of total costs, derived from the fitted polynomial function, is $\$ 7,118$ /TEU. It is necessary to 


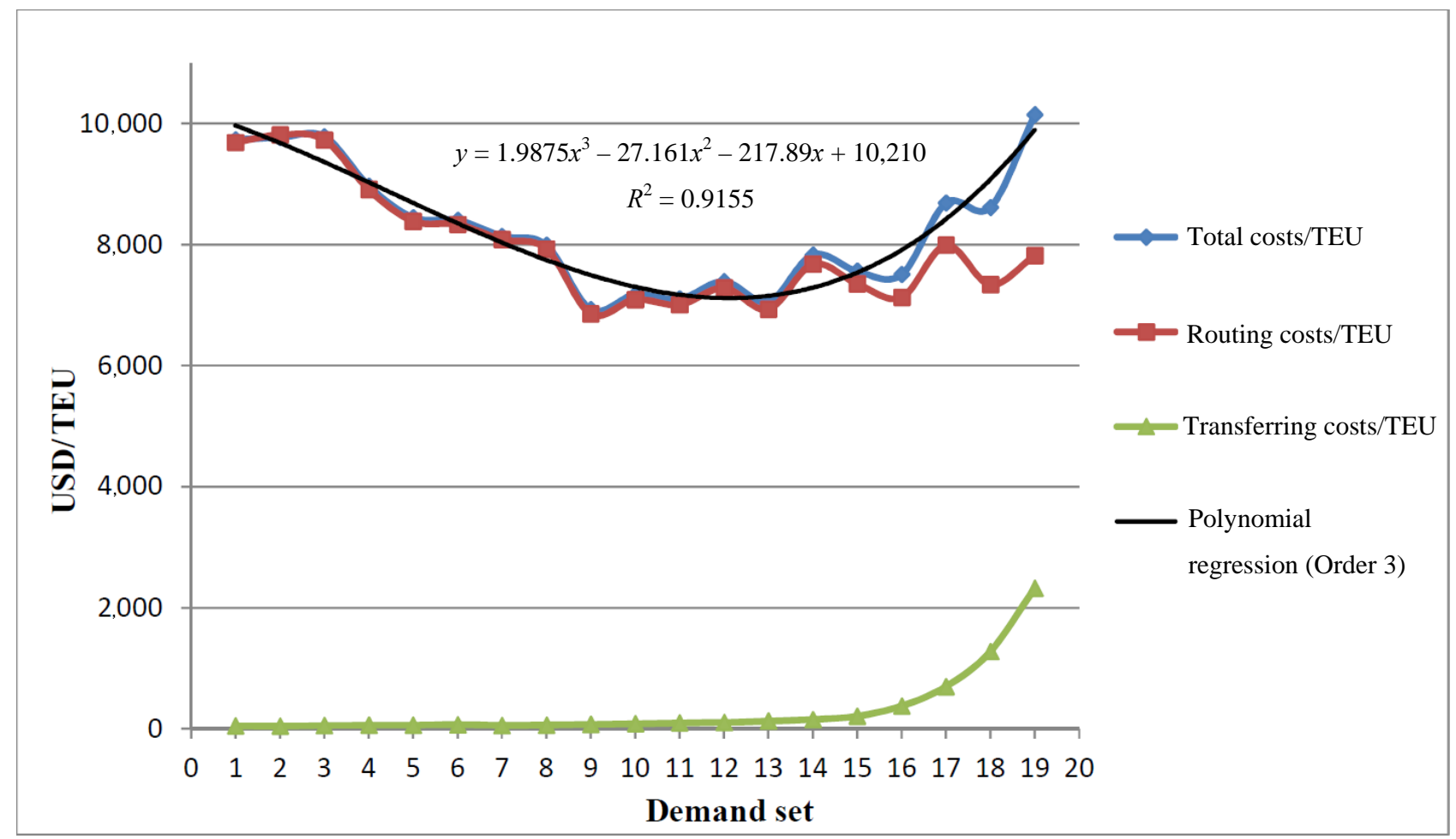

Fig. 5 Total cost per TEUs for different demand sets [8].

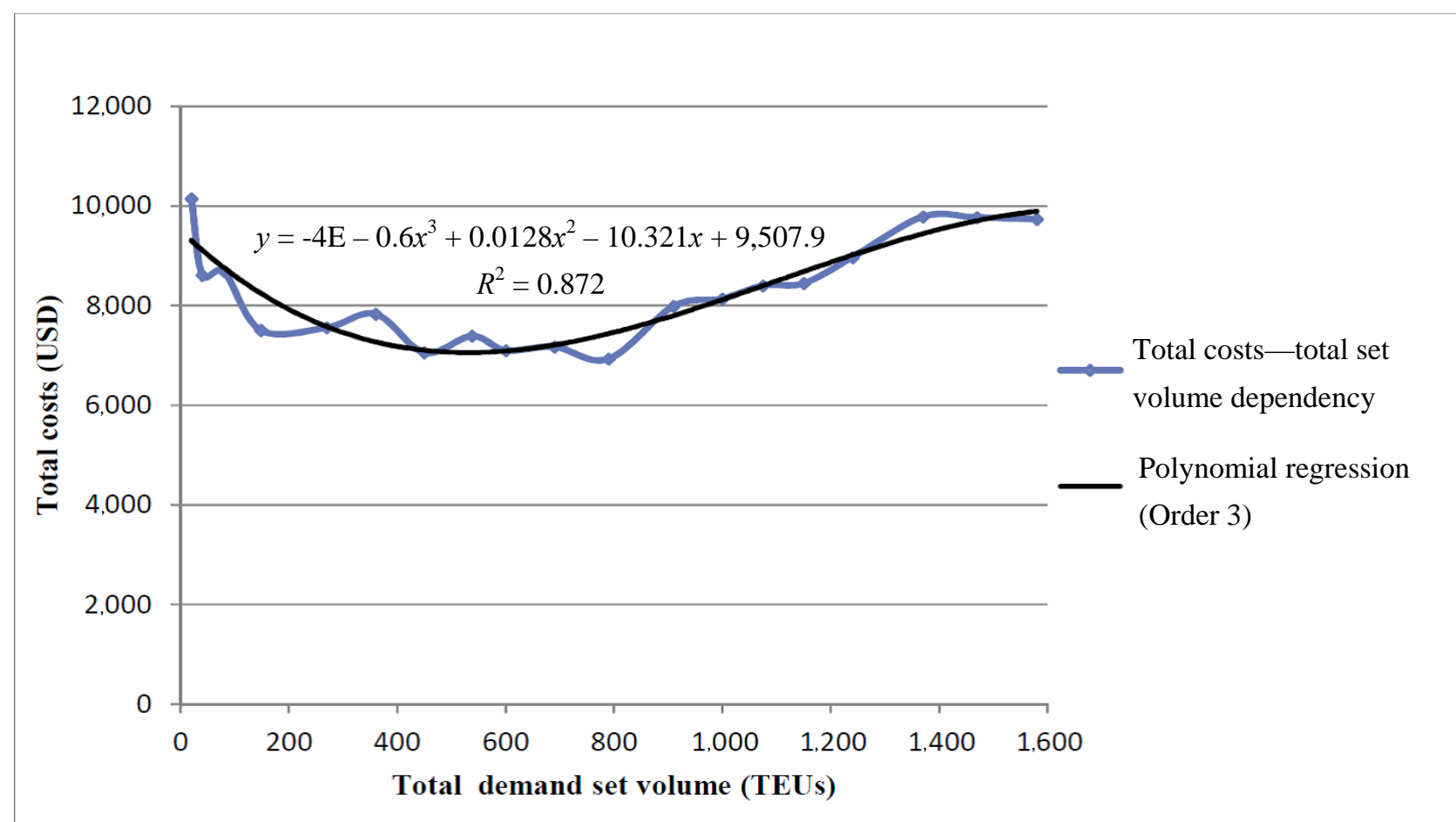

Fig. 6 Total cost per TEU against set volume [8].

mention that this is not the absolute minimum cost. It always depends on the selection of different O-D (origin-destination) pairs and the shipment volumes.

\subsubsection{Optimal Volume}

Fig. 6 shows the analysis of 19 sample sets of shipments. It shows the graph of total costs per TEU 
against total set volume, and polynomial regression curve of the third order.

The minimum total cost per TEU, derived from the fitted function, is obtained at 540 TEUs. It is necessary to mention again that this quantity is not the absolute minimum. It always depends on the O-D pairs. On the other hand, the maximum total cost per TEU is obtained with set volume of 1,594 TEUs. This is because, as the total volume is approaching the capacity of 1,600 TEUs, all the links and modes (including those with the highest costs) have been used.

\section{Conclusions}

The article presents a recent review of maritime transportation. It includes the description of world maritime routes, maritime ships and the costs of maritime transportation. It also discusses the inland rail and road transportation in US and the European continent as the complementary modes for maritime transportation. Included in the analyses are the trends and statistics of the trade between the Czech Republic and US.

The TCMMSP model is then applied in the case study concerning the transportation of a set of five different shipments of a single commodity from Czech cities to US cities.

Twenty different demand sets, each with five shipments of a unique O-D pair and volume, were generated and the solutions analyzed. Four different analyses were conducted: total cost per TEU, optimal set volume, optimal route and port use analysis.

In the TCMMSP model, the cost of transfer is fixed regardless of the TEUs. The cost could be changed to unit cost and then multiplied by the number of TEUs transferred. Future research could also include the inland waterborne transportation in the European continent, because this mode of transportation is becoming more important. One of the next crucial steps is to obtain more accurate input data, such as transportation costs of all modes, capacities of links and nodes of the transportation network.

\section{Acknowledgments}

The authors acknowledge support from the EU-US Atlantis Programme (Project Title: Transatlantic Dual Master's Degree Program in Transportation and Logistics Systems). This project and research is also co-funded by the European Commission's DGEAC (Directorate General for Education and Culture) under Agreement 2010-2843/001-001-CPT EU-US TD.

\section{References}

[1] Bureau of Transportation Statistics. 2013. "Pocket Guide to Transportation 2013 and Innovative Technology Administration." Bureau of Transportation Statistics. Accessed April 6, 2014. http://www.rita. dot.gov/bts/publications/pocket_guide_to_transportation/ 2013/economic_competitiveness/table_04_07.

[2] UNCTAD (United Nations Conference on Trade and Development). 2013. "Review of Maritime Transport." UNCTAD. Accessed April 6, 2014. http://unctad.org/en/PublicationsLibrary/rmt2013_en.pdf.

[3] European Commission. 2014. "Main Tables." European Commission. Accessed April 6, 2014. http://epp.eurostat.ec.europa.eu/portal/page/portal/transpo $\mathrm{rt} /$ data/main_tables.

[4] European Commission, Eurostat. 2014. "Energy, Transport and Environment Indicators." European Commission, Eurostat. Accessed April 6, 2014. http://epp.eurostat.ec.europa.eu/cache/ITY_OFFPUB/KSDK-13-001/EN/KS-DK-13-001-EN.PDF.

[5] MARAD (Maritime Administration). 2011. "US Water Transportation Statistical Snapshot." US Department of Transportation, Maritime Administration. Accessed April 6, 2014. http://www.marad.dot.gov/documents/US_Water _Transportation_Statistical_snapshot.pdf.

[6] European Commission. 2014. "Europe's Seaports 2030: Challenges Ahead." European Commission. Accessed April 6, 2014. http://europa.eu/rapid/press-release MEMO-13-448_en.html.

[7] Public-Private Infrastructure Advisory Facility. 2014. "Intermodal Freight Systems." Public-Private Infrastructure Advisory Facility. Accessed April 6, 2014. http://www.ppiaf.org.

[8] Toman, P. 2014. "Transatlantic Maritime Transportation between the Czech Republic and the United States." Dissertation, University of Texas at El Paso.

[9] US Census Bureau. 2014. "Trade in Goods with Czech Republic.” US Census Bureau. Accessed April 6, 2014. 
http://www.census.gov/foreign-trade/balance/c4351.html.

[10] Grossmann, H., Otto, A., Stiller, S., and Wedemeirer, J. 2007. "Growth Potential for Maritime Trade and Ports in Europe.” Intereconomics 42 (4): 226-31.
[11] Hernández, S., and Peeta, S. 2013. “A Carrier Collaboration Problem for Less-than-Truckload Carriers: Characteristics and Carrier Collaboration Model.” Transportmetrica A: Transport Science March: 1-23. 